\title{
Educating Nurses and Improving Their Resilience During the Covid-19
}

\author{
Mahdieh Motie ${ }^{1}$, Monire Baluchi ${ }^{2}$, Reza Dehnavieh ${ }^{3}$ and Khalil Kalavani ${ }^{4 *}$ \\ ${ }^{1}$ Faculty of Nursing, Islamic Azad University of Tehran, Iran \\ ${ }^{2}$ Institute for Future Studies in Health, Kerman University of Medical Sciences, Iran \\ ${ }^{3}$ Associate Professor of Health Services Management, Head of Innovation Center, Institute for Future Studies in Health, Kerman University \\ of Medical Sciences, Iran
}

${ }^{4}$ Student Research Center, Management and Leadership Research Center in Medical Education, Kerman University of Medical Sciences, Iran

*Corresponding author: Khalil Kalavani, Student Research Center, Department of Healthcare Management, Faculty of Healthcare Management, Kerman University of Medical Sciences, Iran

\section{ARTICLE INFO}

Received: 幽 December 18, 2020

Published: 慧 January 04, 2021

Citation: Mahdieh Motie, Monire Baluchi, Reza Dehnavieh, Khalil Kalavani. Educating Nurses and Improving Their Resilience During the Covid-19. Biomed J Sci \& Tech Res 32(5)-2021. BJSTR. MS.ID.005323.

\section{ABSTRACT}

COVID-19 has created very difficult conditions for health care providers. They experience a lot of mental and psychological stress. Resilience is an important factor in adapting to new conditions. Nurses need to acquire the skills needed to increase resilience. This article discusses the most important strategies to increase resilience in nurses.

\section{Editorial}

Health professionals work in complex environments and deal with many hard issues and situations. The spread of the Coronavirus and the COVID-19 epidemic has caused hospitals and health staff to be experiencing new conditions. The epidemic has also had a significant impact on nurses' performance and has faced them with several challenges [1], some of which include: stress, fatigue, lack of concentration, feelings of depression, etc. that have led to inappropriate work environment and the incidence of medical errors [2]. The challenges may also prevent nurses from committing to their professional tasks [3]. In other words, nurses' resilience to new conditions is facing serious problems. Resilience refers to individuals' ability to withdraw or cope successfully with adverse conditions. It is a personality trait and a dynamic process. Resilience is not only resistance to harms or threatening conditions, but also the active and constructive participation of the individual in the environment. Education and increasing resilience are a key factor in coping with problems. Resilience may change and have a positive effect on other groups or sectors. Taking managerialsupportive measures, hospital and nursing managers can play an important role in this issue [4]. Educating and improving nurses' resilience is an ongoing endeavor, and nursing managers have a key role in building a resilient nursing workforce. It is vital for nursing managers to find out how to develop resilience among nursing staff [5]. In this article, the main interventions to create or improve nurses' resilience are presented:

a. Highlight the importance of nurses' job. Emphasize lofty goals and professional values. Transmit altruism. To this end, use heroes in this field.

b. Increase spiritual connection, optimism, self-efficacy, and self-care among nurses. 
c. Set aside time for nurses to exercise, rest, do social and family activities, and pay attention to the balance between nurses' work and life.

d. Facilitate social relations. Provide opportunities for collaboration outside the workplace so that nurses can interact well with each other and thus boost their morale.

e. One person's resilience affects other peoples. Try different ways to spread resilience in your hospital.

f. Emphasize nurses' strengths, and support your colleagues in different ways. Show that you are satisfied with the nurses' work.

g. Provide continuous education and training courses to increase resilience.

h. Evaluate nurses' resilience regularly and take measures to maintain and improve it.

\section{Author Contributions}

All authors have read and approved to the manuscript.

ISSN: 2574-1241

DOI: $10.26717 /$ BJSTR.2021.32.005323

Khalil Kalavani. Biomed J Sci \& Tech Res

CC (P) This work is licensed under Creative BY Commons Attribution 4.0 License

Submission Link: https://biomedres.us/submit-manuscript.php

\section{Funding}

The authors received no financial support for the research.

\section{Conflicts of Interest}

There are no conflict of interest for the authors of this article.

\section{References}

1. Buheji M, Buhaid N (2020) Nursing Human Factor During CoVID-19 Pandemic. International Journal of Nursing 10(1): 12-24.

2. Hall LH, Johnson J, Watt I, Tsipa A, OConnor DB (2016) Healthcare staff wellbeing, burnout, and patient safety: a systematic review. PloS one 11(7): e0159015.

3. Ulrich CM, Rushton CH, Grady C (2020) Nurses Confronting the Coronavirus: Challenges Met and Lessons Learned to Date. Nursing Outlook 68(6): 838-844.

4. Dehnavieh R, Kalavani K (2020) Management-supportive measures for managers of healthcare organizations during the COVID-19 epidemic. Infection Control \& Hospital Epidemiology 41(7): 878.

5. Jackson D, Firtko A, Edenborough M (2007) Personal resilience as a strategy for surviving and thriving in the face of workplace adversity: a literature review. J Adv Nurs 60(1): 1-9.

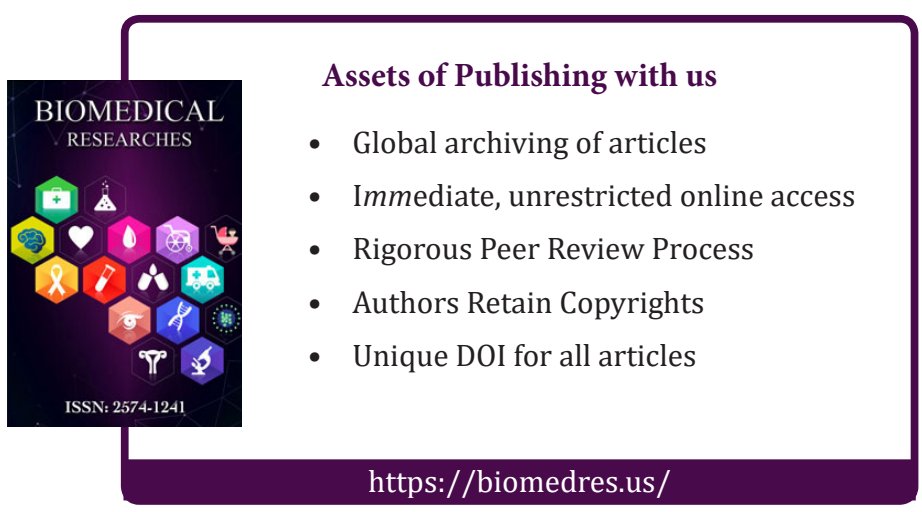

